\title{
AVALIAÇÃO, REFLEXÃO E PESQUISA NA FORMAÇÃO INICIAL DE PROFESSORES/AS
}

\author{
Itamar Mendes Da SiLva*
}

Recebido em: 10 de maio de 2008

Aprovado em: 12 de dezembro de 2008

\begin{abstract}
* Doutor em Educação pela Pontifícia Universidade Católica de São Paulo. Atualmente é professor do Programa de Pós-Graduação em Educação da Pontifícia Universidade Católica de Campinas - PUC-Campinas. E-mail: imendess1@uol.com.br,imendess@puc-campinas.edu.br
\end{abstract}

Resumo: O presente artigo discute procedimentos de acolhimento da reflexão e da pesquisa, mediadas pela avaliação no processo de formação inicial de professores - primeiros anos do curso de pedagogia. Explicita a mudança no envolvimento dos alunos com a disciplina em que se desenvolveu o trabalho - História da Educação - e com a avaliação da aprendizagem. Constatou-se que a reflexão e a pesquisa constituem alternativas viáveis à aquisição de informações significativas, ao trabalho em equipe e, ainda, podem oferecer perspectivas promissoras à formação inicial de professores.

Palavras chave: Avaliação. Pesquisa. Reflexão. Metodologia. Gestão.

\section{EVALUATION, REFLECTION AND RESEARCH \\ IN UNDERGRADUATE TEACHER TRAINING PROGRAMS}

\begin{abstract}
The present article discusses procedures of reception of reflection and research mediated by evaluation in the process of teachers' initial education - first years of Pedagogy major. It points out changes in the involvement of students with the discipline where the work was developed - History of Education - and with learning evaluation. It was evidenced that reflection and research constitute viable alternatives to the acquisition of significant information and to team work, also offering promising perspectives for teachers' initial education.
\end{abstract}

Key words: Evaluation. Research. Reflection. Methodology. Management.

\section{Introdução}

O conceito alternativo de avaliação baseia-se na perspectiva de interestruturação do conhecimento, entendendo a ação de avaliar como processual e reveladora das possibilidades de construção de um processo educativo mais rico e mais dinâmico.

(SOUZA, 1991, p. 71)

A avaliação tem sido apontada como uma das preocupações mais relevantes de professores/as, alunos/as e instituições de ensino superior. Relacionada a todas as áreas de ação das instituições - ensino, pesquisa e extensão - tem ocupado tempo significativo das discussões no meio universitário e nos órgãos públicos responsáveis pelos sistemas educativos, tanto no que respeita à apren- 
dizagem como a instituições, projetos e programas. Assim, deter-se sobre o assunto parece ser não só relevante como urgente e o presente artigo pretende imiscuir-se na questão relacionando-a com a reflexão e a pesquisa, ou seja, discutir práticas de incitação ao desenvolvimento da curiosidade e do gosto pela pesquisa em alunos/as iniciantes no curso de graduação em Pedagogia mediadas pela avaliação. A reflexão que se empreende indica para a opção didático-metodológica de formar professores/as capazes de pesquisar, refletir e, principalmente, iniciar alunos/as neste mesmo proceder. Coloca-se também na perspectiva de debater a conexão necessária da avaliação com o ensino e a aprendizagem.

As discussões acerca da formação inicial e continuada de professores têm se encaminhado para advogar a importância de se contar com profissionais que valorizem a pesquisa (ANDRÉ, 2001; DEMO, 2003) e se caracterizem como intelectuais (GIROUX, 1997) capazes de refletir e operar os diferentes dados de entrada com os quais se deparam no cotidiano do trabalho. Tem-se desenvolvido considerável número de iniciativas de formação permanente que buscam tratar o tema. Mas o aspecto que entendo ser necessário discutir mais detidamente sob esta ótica é a formação inicial. Entendo que o binômio reflexão-pesquisa constitui condição sine qua non da formação inicial de professores/as, especialmente no curso de Pedagogia, pois não se reflete o fazer sem que se tenha a perspectiva, o entendimento e a prática da pesquisa como atividade fundamental à docência.

Também é central, para essa formação, a proposição, realização, análise de pesquisas e a aplicação de resultados, em perspectiva histórica, cultural, política, ideológica e teórica [...]. (BRASIL, 2005, p. 07)

Quando se fala em professor que pesquisa e reflexão se pensa imediatamente num conjunto de atributos que devem ter os/as profissionais da educação neste início de século XXI. Ocorre que esta discussão não é nova na história da educação brasileira, mas de longa data.

Os Pioneiros da Educação Nova, na já distante década de 1930, ao lado da defesa da co-educação na escola pública, laica, gratuita e obrigatória, concebem o professor intelectual e cientista social, funções que não prescindem da reflexão e da pesquisa como fonte organizativa de seu fazer pedagógico. Afirmam em seu Manifesto ${ }^{1}$, destinado ao "povo e ao governo", que o professor deve ser profissional diferenciado e possuidor de formação geral, "cultura múltipla e bem

1 O Manifesto dos Pioneiros da Educação Nova é um documento de domínio público disponível para consulta em http://www.pedagogiaemfoco.pro.br/heb07a.htm e foi apresentado ao povo e ao governo em 1932 por um grupo de educadores/as e intelectuais liderados por Fernando de Azevedo. 
diversa", de tal forma solidificada que nada deve escapar aos seus instrumentos de análise da realidade, pois:

[...] as alturas e as profundezas da vida humana e da vida social não devem estender-se além do seu campo visual; elle deve ter o conhecimento dos homens e da sociedade em cada uma de suas phases, para perceber, além do aparente e do ephemero, 'o jogo poderoso das grandes leis que dominam a evolução social', e a posição que tem a escola, e a funcção que representa, na diversidade e pluralidade das forças sociaes que cooperam na obra da civilização. (p. 55)

A força que a questão ganha atualmente inclui-se no movimento de mudança dos fins da educação exigidos pela sociedade que vive processos de transformação acelerados e de criação de novas formas de ver, viver e produzir. Assim, passa a ser entendimento geral de que é função da educação preparar as novas gerações para o auto-governo, o self-governement defendido por John Locke durante o século XVII como objetivo final da educação do gentleman (LOCKE, 1973) ou para a autonomia de aprender, como apresenta a Unesco em seu relatório editado em 1996, que aponta caminhos para a educação no século XXI (DELORS, 2003). Advoga-se ainda que estes processos devem ocorrer de forma participativa e possibilitar a reflexão e a crítica. Alunos/as e professores/as críticos/as, reflexivos/as e preparados/as para o exercício da cidadania surgem como exigência da realidade atual e passam a permear os discursos e documentos oficiais.

Ao observador menos avisado que ouve estas declarações, quase homogêneas, fica parecendo que as contradições terminaram e que agora cumpre fazer com que a educação deixe de lado seu caráter excludente e de seleção social para, preocupada com a formação integral e promoção do indivíduo, ser capaz de oferecer a todos/as patamares semelhantes de possibilidades de inserção na sociedade. Os discursos, antes considerados progressistas parecem ter sido incorporados indistintamente por amplos setores da sociedade. Mas, é importante destacar que nada disto pode ser considerado apartado das exigências do processo produtivo e de desenvolvimento capitalista.

O modo de produção capitalista faz hoje exigências aos/às trabalhadores/as que superam aquelas do modelo industrial organizado nos moldes do taylorismo-fordismo. Requer profissionais preparados para atuar em contextos de constantes mudanças, capazes de solucionar eventuais problemas, que sejam flexíveis e gozem, portanto, de relativa autonomia. Estes/as trabalhadores/as flexíveis, necessários/as ao processo de acumulação flexível e ao modelo toyo- 
tista devem ser preparados/as no âmbito escolar e por professores/as capazes de entender e trabalhar para a formação de pessoas com estas características (ANTUNES, 1995). Porém, como afirma a sabedoria popular: ninguém dá o que não tem ou ensina o que não sabe. Assim, torna-se imperativo intervir na formação dos/as professores/as para que possam fazer frente às exigências que se apresentam para o momento: formar este novo indivíduo reclamado pelo modelo de produção atual.

A escola vem seguindo a proposta do sistema capitalista, isto é, ela continua sendo classista e dual, com intuito de manter a ordem vigente. Isso significa dizer que existe uma escola para a burguesia, que é uma minoria (e que detêm os meios de produção), e outra para o povo (os trabalhadores), que é uma maioria. Por conta disto, a ideologia se faz muito presente na educação, uma vez que transmite parcialmente a realidade à classe trabalhadora, para que estes se enquadrem nos padrões pré-estabelecidos pelos dominantes e aceitem sua condição como se fosse uma fatalidade. (Elaine²)

Esta constatação, longe de afiliar-se ao corolário crítico-reprodutivista (BOURDIE; PASSERON, 1992), pretende incitar a reflexão de modo que se possam explicitar as contradições existentes neste modelo e possíveis formas de atuar na resistência (GIROUX, 1986) interna e externa à escola que aponta e constrói caminhos alternativos.

Constatar que o/a trabalhador/a necessário/a a este início de século não é mais aquele simples reprodutor "tão forte quanto estúpido" requerido pelo modo de produzir do tayorismo-fordismo pode ser considerado como avanço, mas não como processo de eliminação da exploração. Não se trata de uma crise de consciência dos capitalistas que passaram a entender como necessário superar o embrutecimento humano dado na organização do trabalho no modelo taylorista-fordista, mas do entendimento de que com os novos modos de produzir se encontrou forma mais adequada de maximizar lucros. Assim, as contradições permanecem e a assunção de terminologia progressista não passa de tática dissimuladora - ideológica - dos reais interesses dominantes, ou seja, manter o status quo.

Trabalhar para construir formas de resistência propositivas que superem exigências de formação de trabalhadores/as para simplesmente atender ao modo de produção atual e criem condições para nova prática e perspectiva voltada ao exercício da cidadania plena, ou seja, usufruir "dos bens materiais,

2 Os nomes utilizados são fictícios. 
simbólicos e políticos" (SEVERINO, 1998, p. 99) construídos socialmente, se torna fundamental aos/às formadores/as. As implicações disto para nossos/as alunos/as são muitas quando se fala de mudanças na concepção de ensinar, aprender e avaliar.

\section{O/a Educador/a Desejado/a para estes Novos Tempos}

Pensar o/a educador/a inserido/a num curso de formação de professores/as significa concebê-lo/a numa dupla dimensão, pois educadores/as são todos/as os/as envolvidos/as: os/as que se preparam para atuar e já desenvolvem algum nível de experiência educativa seja por meio de estágios, atividades educativas voluntárias ou mesmo profissionais, vez que existem formados/as em nível secundário - antigo Curso Normal; e os/as que estão responsáveis pela formação inicial dos/as primeiros/as - os/as especialistas, mestres e doutores/as que lecionam nestes cursos. Neste artigo, não se pretende desconhecer esta ambivalência, mas sempre que mencionar o termo professor/a ou educador/a se estará falando dos/as segundos/as e quando se referir a alunos/as ou educandos/as se estará compreendendo os/as professores/as em estágio de formação inicial - alunos/as diferenciados/as, pois se preparam para assumir função docente.

Ao/à professor/a se faz necessário uma sólida formação e uma ampla cultura geral a fim de que possa lidar com os dados presentes na cultura do/a aluno/a, aqueles conhecimentos que traz de outros lugares e de outras experiências, sua visão de mundo e as leituras que faz deste mundo (FREIRE, 1997). Esta postura o/a leva a compreender a importância da resistência aos freqüentes desmandos existentes na área da educação, bem como da formulação de propostas inovadoras que, embora possam não prevalecer de imediato, servem como "estrelas guias” à luta de emancipação.

Os Pioneiros da Educação Nova, já em 1932, parecem nos indicar algo a este respeito:

Se têm essa cultura geral, que lhe permite organizar uma doutrina de vida e ampliar o seu horizonte mental, poderá ver o problema educacional em conjuncto, de um ponto de vista mais largo, para subordinar o problema pedagógico ou dos methodos ao problema philosophico ou dos fins da educação; se tem um espirito scientifico, empregará os methodos communs e todo gênero de investigação scientifica, podendo recorrer a technicas mais ou menos elaboradas e dominar a situação, realizando experiencias e medindo os resultados de toda e qualquer modificação nos processos e nas technicas, que se desnvolveram sob o impulso dos trabalhos scientificos na administração dos serviços escolares. (p. 55) 
Os autores do Manifesto dos Pioneiros criticam fortemente a escola tradicional e propõem mudanças na educação da época apresentando alternativas filosóficas e metodológicas. Críticas feitas por educadores/as progressistas (SAVIANI, 2003) ao movimento e suas práticas focaram, não sem razão, a prevalência do aspecto técnico sobre o filosófico, mas o que demonstra o trecho inicial do manifesto é diferente disto, pois deixam claro que as técnicas, consideradas como meios, devem subordinar-se aos fins, ou objetivos políticos da educação. Assim, é possível entender que as experiências afiliadas ao movimento da escola nova deram muito pouco crédito a este aspecto do Manifesto e/ou o desconsideraram completamente.

A função educativa é uma questão política fundamental, pois, devendo colocar-se em sintonia com a sociedade, nem por isto pode deixar de questionar o status quo e propor inovações. É desta forma que concebem o/a educador/a inserido/a na sociedade como sujeito que pode influenciar seus destinos. Para tanto, deverá ser formado em nível superior, o que só passou a ser considerado e previsto na legislação em 1996 com a edição da Lei de diretrizes e Bases da Educação Nacional no 9394. Foram necessários 64 anos para que, de fato, se entendesse a necessidade da medida.

$\mathrm{O} / \mathrm{a}$ educador/a que se torna sujeito do fazer é aquele/a capaz de pesquisar e de refletir sobre as pesquisas feitas criando conhecimento e a ensinar a pesquisar e a refletir. Assume o papel de sujeito da atividade educativa na medida em que coordena, orienta, intervém, articula, motiva e avalia - gere os processos de aprendizagem no âmbito da sala de aula. Não é superior ao/a educando/a, mas se caracteriza como alguém que possui conhecimento diferenciado e aprofundado em determinada área e, exatamente por isso, tem condição suficiente para estabelecer metas para o trabalho a ser desenvolvido por todos/as.

Ao proceder desta maneira, reflete e ensina a reflexão, pois não se pode lograr obter êxito numa empreitada desta se não houver compromisso com a democracia e a transparência nas ações pedagógicas desenvolvidas na sala de aula, se não houver processo de discussão no qual o/a professor/a coloca seu conhecimento a serviço da promoção dos/as alunos/as e sua constituição enquanto sujeito histórico e conhecedor/a que pode, numa relação de horizontalidade, realizar trocas com seus pares. (FREIRE, 1996)

Tal procedimento serve como incitação à outra face da reflexão que é sua fornecedora de matéria prima: a pesquisa. Esta é o ponto de partida e mesmo o caminho necessário para se alcançar o conhecimento. Daí a necessidade de se buscar freqüentemente as mediações, a conexão entre os fatos, o aprofundamento teórico e a busca de informações em todas as atividades realizadas. 
[...] realizar pesquisas que proporcionem conhecimentos, entre outros: sobre seus alunos e alunas e a realidade sociocultural em que estes desenvolvem suas experiências nãoescolares; sobre processos de ensinar e de aprender, em diferentes meios ambientalecológicos; sobre propostas curriculares; e sobre a organização do trabalho educativo e práticas pedagógicas. (BRASIL, 2005, p. 09)

Trata-se de desenvolver a postura de pesquisador/a em quem terá pela frente a tarefa de ser guia de tantas outras pessoas no caminho do acesso ao conhecimento. Desta forma, a experiência discutida a seguir se coloca na perspectiva de oferecer conseqüência às reflexões feitas e às opções daí emanadas e declaradas até aqui.

\title{
A Reflexão e a Pesquisa como Instrumentos de Ensino e Avaliação
}

\begin{abstract}
Este trabalho fez com que as perspectivas do começo do trabalho evoluíssem e saíssem um pouco do senso comum. Ver a educação com um olhar amplo, em suas várias dimensões. Desde a educação como instrumento para a conscientização política, como educação contra o preconceito, através da inclusão. (Bruna)
\end{abstract}

Ao longo dos anos, fui constatando que os/as alunos/as do Curso de Pedagogia se motivavam bastante quando não discutiam apenas a História da Educação de tempos passados - alguns já longínquos como Grécia e Roma antigas, ou Jesuítica, do Brasil Colônia -, mas fatos recentes da educação dos quais haviam ouvido falar ou lido algo a respeito. Também constatara que os/as alunos/as podiam discutir e emitir opiniões seguras sobre a educação jesuítica ou romana, mas apresentavam dificuldade para se posicionar frente aos acontecimentos mais atuais, já que, quando muito, estavam informados/as sobre o assunto e repetiam a opinião da mídia, como poderia fazer qualquer pessoa de cultura mediana interessada em ler jornais ou acompanhar noticiários no rádio ou na televisão. Tais constatações parecem corroborar Henry Giroux (1997, p. 97-98) quando afirma que, na escola:

...a relação entre teorias e "fatos" é muitas vezes ignorada, tornando, assim, difícil que os estudantes desenvolvam um aparelho conceitual para investigar, em primeiro lugar, a natureza ideológica e espistemológica daquilo que constitui o "fato". Finalmente, a pedagogia [...] tanto cria quanto reproduz relacionamentos sociais em sala de 
aula que são não apenas enfadonhos para a maioria dos alunos, mas também, e principalmente, mistificadores. Em vez de desenvolver pensadores ativamente críticos, tal pedagogia produz estudantes que têm medo ou são incapazes de pensar criticamente.

Face estas constatações e à perspectiva necessária de propiciar o entendimento da educação atual, me propus a construir com os/as alunos/as, a partir do segundo semestre de 2000, um "arquivo comentado de notícias" acerca da educação a ser realizado ao longo do semestre, ao qual dei o nome Dossiê Educação. O trabalho foi sendo avaliado e aperfeiçoado ao longo do período de sua realização e, em alguns períodos, tornou-se interdisciplinar com a participação das disciplinas Filosofia da educação, Sociologia da Educação e Novas Tecnologias.

As notícias poderiam ser de mídias variadas: jornais, revistas, meio eletrônico. Os jornais poderiam ser de grande circulação, jornais de bairro, de associações, sindicatos etc. As revistas poderiam ser as semanais de grande circulação ou quaisquer outras de tiragens menores e/ou "vocacionadas" para a área da educação. Os sítios eletrônicos poderiam ser de variadas naturezas, mas não poderiam ser a versão eletrônica de jornais e revistas disponíveis em forma impressa.

Em todos estes veículos dever-se-iam procurar matérias que enfocassem a educação em algum de seus aspectos. Houve alunos/as que procuraram ligar este trabalho com um único tema de interesse e que, no mais das vezes, coincidia com o que pretendia pesquisar em seu Trabalho de Conclusão de Curso - TCC. A maioria, no entanto, se interessou por temas variados.

Apesar de me interessar por reportagens voltadas para as políticas
públicas, aprendi que o sistema educacional escolar é muito com-
plexo, e engloba atitudes de governantes, de educadores e coordena-
dores, de pais, e de alunos. Não posso e não devo apontar culpados
pela má qualidade de ensino, mas devo como futura educadora me
esforçar para obter uma formação de qualidade e proporcionar aos
meus futuros alunos uma aprendizagem significativa. Este trabalho
tem uma parcela em minha formação, obrigada pela oportunidade.
(Cíntia)

O início do trabalho transcorre em clima de descoberta, de novidade e até de perplexidade diante de uma atividade absolutamente inusitada, pois os/as alunos/ as confessam não se interessarem pela leitura de jornais, revistas. Também não consideravam possível que nestes veículos comuns fosse encontrado material 
de interesse da educação que pudesse ser discutido num curso de graduação. No entanto, na medida em que o tempo passava e a pesquisa se desenvolvia, integravam-se e passavam a se envolver intensamente com o trabalho.

Através desse levantamento de dados foi possível perceber a necessidade do professor estar informado e conseqüentemente interado sobre novos métodos educacionais e tendências tecnológicas, sendo que essa interação ocorre através da informação, seja ela obtida através dos jornais, revistas ou meios eletrônicos. (Gilvânia.

Através deste dossiê, pudemos encontrar muitas reportagens sobre a educação e assim perceber o que realmente está acontecendo com a educação no Brasil. Tanto as dificuldades como as facilidades poderão ser vistas neste trabalho. (Janilene)

O trabalho desenvolvido buscou criar uma perspectiva capaz de trazer aos/às alunos/as a possibilidade de construir postura reflexiva e atenta à educação, acerca de seus diversos problemas e propostas concretizadas, suas mazelas e vicissitudes, em suma, apreender a história da educação se fazendo, o que significou, sem dúvida, modificação na forma de conceber, ensinar e avaliar na disciplina em questão.

Procurou despertar uma postura curiosa e investigativa, assim como elevar os/as alunos/as à condição de construtores/as de sua consciência crítica e possibilitar o exercício da produção de texto que se apresentou em variados níveis.

Este trabalho, com certeza, vem acrescentar em nossa formação, pois depende de nós profissionais da educação mudarmos esta realidade e fazermos do ensino em nosso país algo que servirá de orgulho para todos, queremos que futuramente não haja mais crianças fora da escola, que todos tenham as mesmas oportunidades de crescimento, $e$ que a luta para um melhor ensino tenha sido conquistado por todos. (Gláucia)

Permitiu ainda o confronto com valores e pré-conceitos acerca da educação, aproximando o/a aluno/a da realidade, das questões mais pontuais sobre o ensino - como a reflexão sobre a progressão continuada, a escola pública, projetos desenvolvidos, metodologias inovadoras - e dos problemas enfrentados no cotidiano escolar. Também permitiu analisar o conjunto de fatores econômicos e sociais envolvidos nessas questões e explorar as intenções subjacentes aos/as autores/as, a linguagem utilizada, as posturas ideológicas. 
Há algumas escolas públicas que, com a participação da sociedade organizada, conseguem superar as deficiências materiais e oferecer uma educação de qualidade. Se não contam com a sofisticação das escolas particulares, têm um profundo compromisso com a comunidade e estão empenhadas na formação integral dos alunos. Isso é bastante è̀s vezes é mais importante do que toda a tecnologia oferecida por escolas consideradas de primeira linha. (Maria Angela)

Outra questão que eu quero destacar é a política de cotas raciais, este assunto é polêmico, mas acredito que aos poucos podemos ter uma sociedade mais justa, pois se já que não podemos mudar o nosso passado, podemos pelo menos lutar por um futuro mais justo. Fico indignada quando escuto que a política de cotas é uma injustiça, mas preciso ser tolerante e respeitar a opinião das outras pessoas. (Cíntia)

O desvelar da nova realidade que se apresentou ao entendimento provocou crescimento em reflexão no nível de profundidade possível a estes/as alunos/as - professores/as em formação - que alargou suas perspectivas e visões de mundo. Isso se deu, porém, em temporalidades diferenciadas, dada a observação do ponto de partida de cada um/a e não apenas o produto final consagrado em um texto sem que o contexto seja considerado. Importante destacar que cabe à avaliação captar a complexidade deste processo de crescimento individual.

A crise pela qual passa o ensino no Brasil é de grandes proporções, mas há muitas possibilidades de se reverter essa situação com a construção de outro conceito de educação, de forma concreta, consciente, com o comprometimento dos profissionais da educação e a participação da comunidade. (Maria Angela)

Apesar de tudo, muitas coisas boas também estão acontecendo, hoje as pessoas começam a ver que sem educação não há desenvolvimento, e assim vemos o aumento de alunos que haviam abandonado a escola, hoje retornam às salas de aula. Isto também se dá pela mídia, nunca se falou e se cobrou tanto para que tenhamos um ensino de qualidade, nos últimos anos as notícias relacionadas à educação têm sido a pauta social mais veiculada no país [...]. (Gláucia)

É necessário esclarecer a todos que estão envolvidos no processo educativo que a escola não tem a mera função de transmitir conhecimentos. Seus objetivos vão muito além disto e são muito mais profundos, pois envolvem o processo de humanização, de desenvolvimento da criticidade nos alunos, permitindo que transformem o meio que estão inseridos. É importante termos em mente que a educação não 
é o único meio de transformar a sociedade, mas sem ela a transformação não ocorre. (Elaine)

Este trabalho foi muito interessante para a minha formação de educadora, pois aprendi que não posso deixar de analisar o sistema educacional. Preciso conhecer seus problemas, as questões que devemos lutar por mudanças. Mas preciso também me espelhar nos grandes educadores que fazem história em suas comunidades. Apesar de não apresentar nenhuma reportagem que mostre a atitude de professores que fazem a diferença na educação, pude ler e refletir reportagens que mostram professores nota dez, que mostram projetos pedagógicos que valorizam os alunos, e também aprendi que somente conhecer o problema não basta. (Cíntia)

Fica claro, assim, que, do ponto de vista didático, este trabalho se prestou também para a composição da avaliação inclusa na concepção de que se faz no decorrer do processo, baseado no registro e contando com a participação do/a aluno/a. Concebeu-se a avaliação desenvolvida como possuindo várias dimensões - objetiva, subjetiva e relacional.

\section{O Registro como Instrumento de Avaliação}

Em todo processo de avaliação requer-se uma capacidade de observação e registro por parte do professor e, se possível, por parte do aluno também. (MASETTO, 2003, p. 156)

No trabalho que se desenvolveu com o Dossiê Educação, que envolveu alunos/as do primeiro ano do curso de pedagogia, se procurou fazer com que cada uma de suas fases fosse observada e registrada pelo professor, de forma a comporem-se como instrumentos de avaliação. Também os/as alunos/as foram produzindo seus registros do processo, o que lhes possibilitou a consciência de seu envolvimento e desempenho.

A avaliação compõe o processo educativo e caracteriza-se como meio de se obter informações e subsídios para correções e melhorias que forem necessárias. Nela elaboram-se juízos de valor, qualitativos ou quantitativos, sobre uma determinada atividade isolada ou processo, sobre um fazer, uma ação.

A organização prevista propôs uma discussão mensal acerca do temas levantados pelos/as alunos/as. A discussão foi sempre precedida de pesquisa realizada pelos/as alunos/as e escolha de textos sobre educação presentes na mídia. Escolhido o texto, proceder-se-ia a sua apresentação e comentário escritos para discussão em aula. 
Pelo o que eu pude perceber através de minhas reflexões e das reflexões de meus colegas de classe, que divulgaram suas reportagens em assembléias e debates, que a educação tem muito que melhorar, onde existem vários problemas, mas existem também vitórias. (Cíntia)

Este registro do processo que inclui a postura investigativa e explicita a intenção de educar pela pesquisa (DEMO, 2003), possibilitou a troca e o cotejamento crítico de suas produções e dos colegas levando a modificações nos moldes de ver e de pensar e em seus próprios textos. Pois, como aponta Hadji (1994, p.108) “[...] a avaliação deve retomar a ligação com o produtor, e dizer-lhe alguma coisa acerca da sua produção que lhe permita progredir com vistas a melhores produções."

Na sala de aula, o professor fazia um primeiro levantamento dos temas e distribuia os/as alunos/as em grupos para que apresentassem seus textos escritos a partir dos artigos escolhidos. Nestes grupos temáticos, transcorriam discussões coordenadas pelos/as alunos/as presentes e a escolha de um texto escrito por um/a aluno/a para ser apresentado ao conjunto da turma.

Após a discussão nos grupos, iniciava-se a discussão geral - plenária - com a apresentação do resultado das discussões e o texto escolhido. Esta fase é de debate e momento em que o professor problematizava as discussões dos grupos e buscava aprofundar as idéias, desvelando as possíveis intenções latentes aos artigos e oferecendo referências adicionais de análise aos/as alunos/as. Os/as alunos/as também expressavam posicionamentos e opiniões que iam crescendo em reflexão e fundamentação no transcorrer do semestre.

Este processo era avaliado no final do encontro pelos/as participantes, momento em que se buscavam formas de aperfeiçoar constantemente o fazer pedagógico de modo a construir uma relação de reflexão e pesquisa cada vez mais forte. Esta ambiência de pesquisa é que poderá lograr êxito no processo de formação inicial de professores/as capazes de refletir e pesquisar sobre o mundo e sobre o cotidiano e não apenas acerca das produções científicas consagradas.

A avaliação desenvolvida se configurou como processual e somativa. Entretanto, pretendeu-se a avaliação com foco processual, mesmo não prescindindo do aspecto medida e assentindo em fazê-la também somativa.

Neste caso, é somativa, pois a cada discussão mensal se observam certos quesitos, se registra os desempenhos e se atribui conceitos numéricos parciais que somados ao final do semestre compõem $40 \%$ da nota final. Os quesitos examinados: 
1) pesquisa $^{3}$ - no qual o/a aluno/a deve comparecer à aula com um artigo datado daquele respectivo mês, que encontrou nas mídias definidas como possíveis para o trabalho;

2) a produção de texto que apresenta e analisa o assunto discutido no referido artigo, de modo que, quando da discussão em sala de aula, não se necessite recorrer ao artigo, mas somente ao texto produzido;

3) a participação do/a aluno/a na discussão de seu texto e dos que forem apresentados em seu pequeno grupo de discussão e na plenária;

4) postura condizente com a profissão de educador/a que escolheu e que se guia por determinados princípios éticos de respeito às idéias alheias, mesmo no debate discordante;

5) cumprimento de prazos. Estes quesitos todos são reunidos em um conceito parcial para cada atividade mensal e varia de 0,0 a 1,0, perfazendo um total de 4,0 pontos do total do trabalho. (MASETTO, 2003, p. 158)

Também é formativa devido às participações parciais informadas mês a mês aos/às alunos/as, que podem ser revistas tanto para o mês seguinte (próxima produção e participação) quanto para o produto final, expressão do crescimento de análise e engajamento com o processo que cada um/a conseguiu empreender. E, pelo fato de a prática do registro e seu controle, pois o/a aluno/a o mantém em seu poder, constituindo elemento fundamental para que se possa auto-avaliar.

A composição final da nota considera e afere cartesianamente os critérios apostos no item somativo correspondentes a $40 \%$ do total. Para o aspecto formativo considera aspectos relativos ao/à aluno/a em relação a ele mesmo, ou seja, o seu ponto de partida e seu ponto de chegada, em relação ao conteúdo desenvolvido e em relação ao grupo ao qual pertence (ANASTASIOU, 2006) e se forma a partir dos registros, de professor e alunos/as. Considera, portanto, os aspectos objetivo, subjetivo e relacional do processo de ensino aprendizagem.

Um e outro procedimento avaliativo, que compõem o processo de avaliação, são de fundamental importância para o desenvolvimento do que se pretende, direcionando-se para o aprofundamento da assunção dos rumos pelos/as envolvidos/as. Assim procedendo, se efetiva o trabalho de formação de professores/as que incorporam em suas práticas cotidianas a reflexão, predispostos à pesquisa

3 Note-se que o termo pesquisa é utilizado aqui não com o rigor terminológico de produção rigorosa de conhecimento segundo um determinado método, mas como procedimento de busca de informações para serem objeto de reflexão, como incitação ao gosto pela busca de conhecer. No caso, os/as estudantes realizam pesquisa em sentido lato. 
e a construção de uma avaliação com características emancipatórias (SAUL, 1988), pois se oferecem condições ao sujeito de conhecer, acompanhar e assumir o controle de sua ação no processo.

A avaliação é uma operação de "leitura da realidade”, “do mundo” (FREIRE, 1997). E, não parece ser outra coisa o que os/as alunos/as conseguiram construir ao longo do processo descrito. A este respeito, observem-se as reflexões abaixo:

A educação brasileira vem apresentando inúmeros problemas; uns mais recentes, outros que carregamos desde a vinda dos jesuitas.

Recentemente foi revigorada a lei que habilita indivíduos que possuem apenas o Colegial Normal (Magistério) completo a lecionarem na Educação Infantil e Ensino Fundamental (ciclo I), ou seja, não é mais necessário haver formação em nível superior. Nesse aspecto, nos cabe algumas perguntas: até que ponto o governo leva à sério o sistema de educação? Que tipo de educadores querem formar? Que tipo de alunos querem "produzir"? Sendo a Pedagogia a ciência da Educação, por que não acham que ela seja essencial ao processo de ensino-aprendizagem? (Maria Angela)

\section{Considerações Finais}

O processo descrito, objeto da análise e reflexão que se empreendeu oferece, ao meu julgamento, alguns outros pontos que os/as formadores/as podem considerar:

1) a questão da identidade do professor vem sendo discutida desde há muito no Brasil; contudo, ainda estamos longe de compreender que é verdadeiramente necessário se promover a formação dos futuros/as professores/as críticos/as e reflexivos/as, capazes de incorporar a atitude pesquisadora em seu cotidiano e propiciar aos/às alunos/as desenvolverem sua curiosidade epistemológica;

2) a realidade pode ser o ponto de partida para o desenvolvimento do gosto pela pesquisa e para aguçar a curiosidade e implementar a prática da reflexão em nossas salas de aula;

3) o registro do processo realizado por alunos/as e professor/a pode ser a chave para um processo de avaliação que considere a diversidade dos alunos/as, suas peculiaridades de desenvolvimento e envolvimento com o conhecimento; 
4) o trabalho com as mídias pode vir a ser um importante ponto de partida para que os/as alunos/as passem a conceber que as fontes de conhecimento podem ser variadas e transcendem as convencionais, quando mediadas pela reflexão séria, criteriosa e sistemática;

5) as modificações no processo de ensino tornaram necessárias modificações no processo de avaliação com incorporação dos/as alunos/as como sujeitos ativos/as da formação e da avaliação que se desenvolveu;

6) a prática da pesquisa e da reflexão se mostram como condição sine qua non à formação de professores/as adequados/as às exigências destes novos tempos, não porque virou "moda" utilizar estes termos, mas porque pode corresponder a uma atividade de verdadeiramente transcender o nível da técnica e buscar refletir acerca dos fins da educação, como advogam os Pioneiros da Educação Nova. Ou como dizem os/as alunos/as:

É necessário esclarecer a todos que estão envolvidos no processo educativo que a escola não tem a mera função de transmitir conhecimentos. Seus objetivos vão muito além disto e são muito mais profundos, pois envolvem o processo de humanização, de desenvolvimento da criticidade nos alunos, permitindo que transformem o meio que estão inseridos. É importante termos em mente que a educação não é o único meio de transformar a sociedade, mas sem ela a transformação não ocorre. (Elaine)

A finalidade da educação é formar seres aptos a governar a si mesmos e não para serem governados pelos outros. O mais importante na construção do homem, não é instruí-lo, mas educá-lo para a vida, para o exercício da cidadania. (Maria Angela)

Por fim, se durante muito tempo negligenciaram-se os itens propostos acima, tomemos como exemplo as palavras desta aluna que propõe um desafio:

Basta agora aprendermos com os erros já cometidos e assim trilharmos um caminho onde todos possam ter as mesmas oportunidades, que o crescimento de cada indivíduo dependa única e exclusivamente das escolhas que faça. ...depende de nós profissionais da educação lutar, cobrar, gritar e acima de tudo começarmos a agir, para que esta luta não seja de uns e outros, mas de todos. Temos que assumir a responsabilidade e lutar para que façamos parte desta história de forma construtiva e transformadora. $O$ amor com que vamos trabalhar será determinante, o entusiasmo é essencial sempre, já conhecemos um pouco mais da nossa realidade, agora nos cabe transformá-la... (Gláucia) 


\section{Referências}

ANASTASIOU, L.G.C. Avaliação, ensino e aprendizagem: anotações para ações em currículo com matriz integrativa. In: SILVA, A.M.M. et al. Novas subjetividades, currículo, docência e questões pedagógicas: na perspectiva da inclusão social. Recife: ENDIPE, 2006.

ANDRÉ, M. (Org.) O papel da pesquisa na formação e na prática dos professores. Campinas: Papirus, 2001.

ANTUNES, R. Adeus ao trabalho? : ensaio sobre as metamorfoses e a centralidade do mundo do trabalho. São Paulo: Cortez; Campinas: Ed. Unicamp, 1995.

BRASIL. MINISTÉRIO DA EDUCAÇÃO/ CONSELHO NACIONAL DE EDUCAÇÃO. Diretrizes Curriculares Nacionais para o Curso de Pedagogia PARECER CNE/CP N ${ }^{\circ}$ : 5/2005.

BOURDIEU, P.; PASSERON, J.C. A reprodução: elementos para uma teoria do sistema de ensino. 3 ed. Rio de Janeiro: Francisco Alves, 1992.

DEMO, P. Educar pela pesquisa. 5. ed. Campinas: Autores Associados, 2003.

DELORS, J. Educação: um tesouro a descobrir. 8. ed. São Paulo: Cortez; Brasília, DF: MEC: UNESCO, 2003.

FREIRE, P. Pedagogia da Autonomia: saberes necessários à prática educativa. São Paulo: Paz e Terra, 1996.

A importância do ato de ler. 34. ed. São Paulo: Cortez, 1997.

GIROUX, H. Teoria crítica e resistência em educação. Tradução de Ângela M.B. Biaggio, Petrópolis: Vozes, 1986.

. Os professores como intelectuais: rumo a uma pedagogia crítica da aprendizagem. Porto Alegre: Artes Médicas, 1997.

HADJI, C. A avaliação, regras do jogo: das intenções aos instrumentos. Portugal: Porto Editora 1994.

LOCKE, J. Ensaio acerca do entendimento humano. São Paulo: Abril Cultural, 1973. (Coleção os pensadores)

MASETTO, M.T. Competência pedagógica do professor universitário. São Paulo: Summus, 2003. 
SAVIANI, D. Escola e democracia: polêmicas do nosso tempo. 36. ed. Campinas: Autores Associados, 2003.

SAUL, A. M. Avaliação emancipatória. São Paulo: Cortez, Autores Associados, 1988.

SEVERINO, A. J. Filosofia da educação: construindo a cidadania. São Paulo: FTD, 1998.

SOUZA, S. Z. L. Revisando a teoria da avaliação da aprendizagem. In: SOUZA, S. Z. L. (Org). Avaliação do rendimento escolar. Campinas: Papirus, 1991. 